\title{
The Materialization Characteristics and Ratio of a New Soil Paste Filling Material
}

\author{
Zhi Wang $\mathbb{D}^{1}{ }^{1}$ Weijian Yu $\mathbb{D}^{1,2}$ and Fangfang Liu ${ }^{1}$ \\ ${ }^{1}$ School of Resource \& Environment and Safety Engineering, Hunan University of Science and Technology, \\ Xiangtan, Hunan, China \\ ${ }^{2}$ Hunan Provincial Key Laboratory of Safe Mining Techniques of Coal Mines, Xiangtan, Hunan, China \\ Correspondence should be addressed to Weijian Yu; ywjlah@163.com
}

Received 3 October 2020; Revised 7 November 2020; Accepted 17 December 2020; Published 29 December 2020

Academic Editor: Hualei Zhang

Copyright (C) 2020 Zhi Wang et al. This is an open access article distributed under the Creative Commons Attribution License, which permits unrestricted use, distribution, and reproduction in any medium, provided the original work is properly cited.

In this paper, the research background is the filling and mining of the landscape mineral paste body in Baixian State, Guangxi, China. The strength test of the new paste filling material is carried out by the materials of coal zircon, red soil, and cement, the best ratio between the materials is obtained, and the hydration mechanism of the new paste filling material is studied by XRD diffraction instrument and SEM (scanning electron microscopy) test. The types of hydration products and microstructure forms of filling materials in different age periods are revealed. The test results show that the optimal ratio of the new paste filling material in the coal mine is the quality ratio of coal zircon: red soil: cement as $6: 2: 1$, and the slurry concentration is $80 \%$, which can not only meet the transportation requirements required by the filling process but also reduce the cost of filling, and with the extension of the maintenance age, the filling material produces more gel products, and the overall structure is more encrypted.

\section{Introduction}

During the mining process, large-scale underground activities have left a large number of goafs, destroying the initial rock stress and causing surface subsidence [1-3]. As the most effective method to control surface subsidence and realize green mining, the filling and mining technology plays an essential role in the process of coal resource mining for its unique mining technique [4]. Paste filling and mining technology has been developed since 1980s, and remarkable achievements have been made in the research of paste filling materials [5]. Cui et al. [6-10] investigated the preparation and performances of new paste-like backfill material, which is primarily made of mine waste materials, such as slag, loess, and lime. Phan and Wang [11] and Zhang et al. [12] experimented the influence of the factors such as material ratio, mass concentration of paste and cement content on the performance of paste filling material, and saturated unconfined compressive strength (SUCS) tests and SEM tests to determine accordingly the optimal proportion of material. Feng et al. [13] and Zhou [14] studied the properties of new filling materials, through a large number of tests, the components, basic mechanical properties, microstructure characteristics, and rheological properties of the filling materials which are analyzed and a method of controlling the stability of the filling body is proposed An et al. [15] and Yu et al. $[16,17]$ analyzed the mechanics characteristic and optimum proportion of mixed backfilling of aeolian and loess and studied the impact laws of original compaction force on the backfilling material and hydraulic support on stress and plastic zone of coal pillars.

A large amount of red soil "waste" deposited on the surface around coal mine are easy to cause safety issues such as collapse, sliding for the rainfall, and complicated terrain in south China. In this paper, a new type of paste filling material is developed by using materials such as red soil and coal zircon. Under the premise of satisfying the requirements of mining technology, the cost of filling material can be minimized, which is of great significance to promote resources utilization and the green mining in south China. 


\section{Material Composition}

According to the purpose of this experiment, the main experimental materials selected are coal zircon, red soil, ordinary Portland cement, and water. The nature of the filling material greatly affects the paste filling process and the quality of the filling body. Therefore, the physical properties, chemical composition, and microstructure of the materials taken should be analyzed before preparing the filling material.

2.1. CoalZircon. The coal zircon used in the test is produced by Zhoujing Coal Mine. After secondary crushing (particle size is not more than $25 \mathrm{~mm}$ ), the coal zircon is generally gray or grayish white (Figure 1). As shown in Table 1, the content of coal zircon with particle size less than $5 \mathrm{~mm}$ in the test reached $43.4 \%$, which meets the coal zircon grade requirements and ensures that different sizes can be filled with each other.

The physical properties of the coal zircon sample are tested, as shown in Table 2. The coal zircon pore is large, low water content, and low density. After analyzed by X-ray diffraction instrument, it can be seen from Table 3 that the content of $\mathrm{SiO}_{2}$ in the mineral components exceeds 1/3; in addition, the coal zircon also contains a lot of quartz, feldspar, and kaolinite Coal zircon expands, disintegrates, and softens strongly when meets water and is difficult to be muddy; therefore, the aggregate properties of coal zircon as filling material are better.

2.2. Red Soil. The red soil used in the test was taken from the surrounding of Zhoujing Coal Mine, which was brownish red, as shown in Figure 2. After drying, the red soil was carried out to the laboratory. And the composition and the physical properties of the red soil are obtained, as shown in Tables 4 and 5, respectively.

In Table 4, the proportion of red soil particle size less than $0.05 \mathrm{~mm}$ accounts for $0.7 \%$, and particle size greater than $5 \mathrm{~mm}$ accounts for $9.3 \%$. Most particles are concentrated on $0.3 \sim 5 \mathrm{~mm}$, and the optimal ratio of particle sizes should be calculated by using the Tabor formula [18]:

$$
\alpha=\frac{d_{60}}{d_{10}}
$$

where $\alpha$ is the coefficient of nonuniformity, and the value is between 4 and $5 ; d_{60}$ is the diameter of the mesh through which $60 \%$ particles pass, $\mu \mathrm{m}$; and $d_{10}$ is the diameter of the mesh through which $10 \%$ particles pass, $\mu \mathrm{m}$.

From Table 4, the red soil particle size parameters are $d_{10}=46.2 \mu \mathrm{m}, d_{60}=211.4 \mu \mathrm{m}$, and $\alpha=4.58$; overall particles are well graded.

In Table 5, the red soil pore is large, medium low water content, and low compression and compactness. The average compression coefficient of red soil is 0.01 , which is lower than that of loess of 0.05 .

From the XRD diffraction of red soil shown in Figure 3, quartz, hematite, kaolinite, and mica are the main chemical

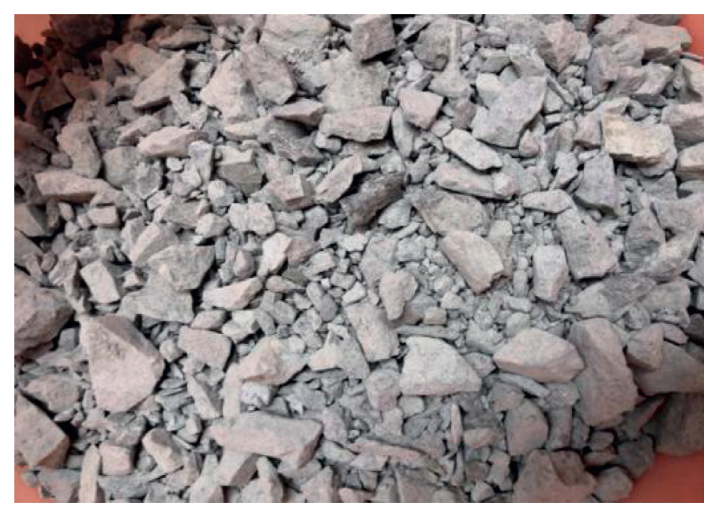

Figure 1: A sample of coal zircon.

TABLE 1: Determination results of particle size composition of coal zircon.

\begin{tabular}{lccccccc}
\hline $\begin{array}{l}\text { Particle size } \\
(\mathrm{mm})\end{array}$ & $>5$ & $5-2$ & $2-1$ & $1-0.3$ & $0.3-0.15$ & $0.15-0.05$ & $<0.05$ \\
\hline Content (\%) & 56.6 & 18.7 & 10.4 & 7.3 & 2.1 & 3.7 & 1.2 \\
\hline
\end{tabular}

compositions of red soil and also a small amount of chlorite and goethite; the content of $\mathrm{SiO}_{2}$ is highest in red soil; $\mathrm{Fe}_{2} \mathrm{O}_{3}$, $\mathrm{KAl}_{2}\left(\mathrm{AlSi}_{3} \mathrm{O}_{10}\right)(\mathrm{OH})_{2}$, and $\mathrm{AlSi}_{2} \mathrm{O}_{5}(\mathrm{OH})_{4}$ are less. $\mathrm{SiO}_{2}$ ensures the strength of the filling material.

The addition of red soil not only fill the pores between the large aggregate particles effectively but can reduce the wear of irregular coal zircon on the inner wall of the pipe in the pipeline transport.

In summary, red soil is a kind of high strength, low compression, and high porosity material, which has certain advantages to make paste filling material.

2.3. Cement. The cement used in the test is PO32.5, a local mine brand ordinary Portland cement. The XRD diffraction pattern of cement sample is shown in Figure 4. The main chemical compositions of cement are tricalcium silicate, dicalcium silicate, calcium aluminate, calcium aluminoferrite, and gypsum. The content of $\mathrm{CaSiO}_{3}$ is about $50 \%$, and also, $\mathrm{CaCO}_{3}$ is the strength source of the cement. Tricalcium silicate and dicalcium silicate have the same hydration reaction with water, and the products are all hydrated calcium silicate $\left(2 \mathrm{CaSiO}_{2} \mathrm{nH}_{2} \mathrm{O}\right)$.

\section{Experimental Analysis}

3.1. Proportioning Design. In order to study the performance of the filling material at different ratios, the cement-sand ratio (mass ratio of coal zircon to cement) was determined to be $6: 1$ based on previous mixing experience; slurry concentration $(X)$ ranged from $76 \%$ to $82 \%$, taking 4 levels; the mass ratio of cement to red soil $(Y)$ ranged from $1: 2,1: 1$, and $2: 1$; in addition, a group of red soil-zircon filling body without cement and a group of concrete filling without red soil were designed for comparison, a total of 5 levels; and the curing age $(Z)$ was 3 days, 7 days, 14 days, and 28 days, separately. A total of 14 groups of experiments were 
TABle 2: Test results of physical parameters of coal zircon.

\begin{tabular}{lcccc}
\hline Density $\left(\mathrm{t} / \mathrm{m}^{3}\right)$ & Volume weight $\left(\mathrm{t} / \mathrm{m}^{3}\right)$ & Porosity (\%) & Water content (\%) & Compression coefficient \\
\hline 2.56 & 1.71 & 40.32 & 2.89 & 0.04 \\
\hline
\end{tabular}

TABle 3: Test results of mineral composition of coal zircon.

\begin{tabular}{lcccc}
\hline \multirow{2}{*}{ Material } & Composition & \multicolumn{3}{c}{$\begin{array}{c}\text { Base ingredient } \\
\text { content (\%) }\end{array}$} \\
& & $\mathrm{Fe}_{2} \mathrm{O}_{3}$ & $\mathrm{Al}_{2} \mathrm{O}_{3}$ & $\mathrm{SiO}_{2}$ \\
\hline Coal zircon & Quartz feldspar kaolinite & 4.01 & 7.84 & 38.46 \\
\hline
\end{tabular}

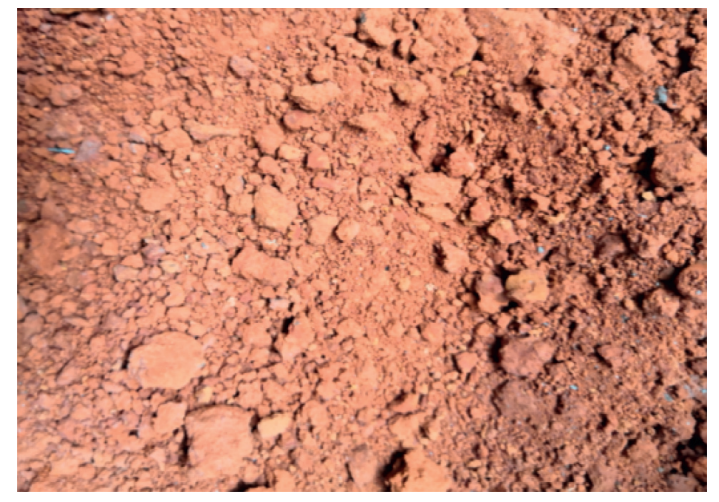

Figure 2: Red soil sample (dry and loose).

designed, and the test factors and horizontal distribution are shown in Table 6.

3.2. Preparation of Specimens. In this test, the cube triple models of $7.07 \mathrm{~cm} \times 7.07 \mathrm{~cm} \times 7.07 \mathrm{~cm}$ were used. According to the mix ratio, the required materials were weighed and reserved. First, the dry material was put in a blender and mixed well, and then, the weighed water was added to get the flowing slurry and measured slurry collapsing degree and bleeding rate. After the paste was injected into the test mold, the surface was scraped with a steel ruler in time, and finally, the specimens were released from the mold after setting, as shown in Figure 5. The specimens were maintained in a constant temperature and humidity standard maintenance box (temperature $20^{\circ} \mathrm{C}$ and humidity $90 \%$ ) to the specified age; after dryness to constant weight, the stone rate and the uniaxial compressive strength were tested.

3.3. Test Results and Analysis. In the test, the collapsing degree, bleeding rate, stone rate, and compressive strength of the filling material were tested, and the results are shown in Table 7. According to the test results, Figure 6-Figure 8 are drawn to analyze the influence of test factors such as the red soil content, the slurry concentration, and the curing age to filling material strength.

From Figure 6 (the abscissa in the figure represents the mass ratio of red soil to cement; A, B, C, D, and E are plain cement, $1: 2,1: 1,2: 1$, and plain red soil), the strength of the filling material shows a downward tendency with the increase in the red soil content. Compared with plain red soil, with the
TABLE 4: Test results of the composition of the red soil particle size.

\begin{tabular}{lccccccc}
\hline $\begin{array}{l}\text { Particle size } \\
(\mathrm{mm})\end{array}$ & $>5$ & $5 \sim 2$ & $2 \sim 1$ & $1 \sim 0.3$ & $0.3 \sim 0.15$ & $0.15 \sim 0.05$ & $<0.05$ \\
\hline Content (\%) & 9.3 & 20.0 & 23.1 & 22.6 & 14.2 & 10.1 & 0.7 \\
\hline
\end{tabular}

increase in the red soil proportion, and the decrease in the cement proportion, the tendency of maximum dry density gradually decreases, while the optimum water content gradually increases. This because the red soil replaces the cement, the wrapping, filling, and cementing effects of the cement are weakened, and the density of the filling body reduces.

From Figure 7, with the increase in slurry concentration, the strength of the filling material shows an upward tendency, and the rate is accelerated. From Figure 8, the tendency to compressive strength of the filling body increases with the extension of the curing age of the test block.

Mine filling slurry should have the following characteristics $[19,20]$ : the collapsing degree of paste should not be less than $20 \mathrm{~cm}$; the bleeding rate should not exceed 3\%; under standard maintenance conditions, the early strength should not be less than $0.1 \mathrm{MPa}$; the strength in 28 days should not be less than $1.5 \mathrm{MPa}$. Based on the above analysis, the optimal mixing ratio of the new paste filling material is the quality ratio of zircon: red soil: cement as $6: 2: 1$, and the slurry concentration is $80 \%$.

\section{Analysis of Hydration Mechanism of Filling Material}

4.1. SEM Analysis of Filling Material. The filling test blocks with the optimum ratio were crushed from the central part, from which the samples with suitable size were selected. After soaked in anhydrous ethanol to terminate the hydration process, it is taken out and dried for gold spray treatment, and the specimens are put into SEM for microstructure analysis. Figures 9-11 show the SEM diagram of hydration products at different ages and magnifications, respectively.

From Figure 9(a), the cement in the paste has been partially hydrated after 3 days of specimen maintenance. A mass floc-like scolecite and needle-like ettringite crystals are produced and distributed in the pores of the material, giving the filling material early strength; however, from Figure 9(b), the ettringite is less abundant and poorly developed in the small crystals and a large amount of cement particles that does not participate in the reaction are stuck to the zircon. The thin particles of red soil are loosely distributed and have many pores. With the extension of the curing age of the filling sample, the hydration reaction of the filling material also continues.

From Figure 10(a), as curing age extends, more and more chemical products are produced in the filling body. The 
TABLE 5: Test results of the physical properties of the red soil.

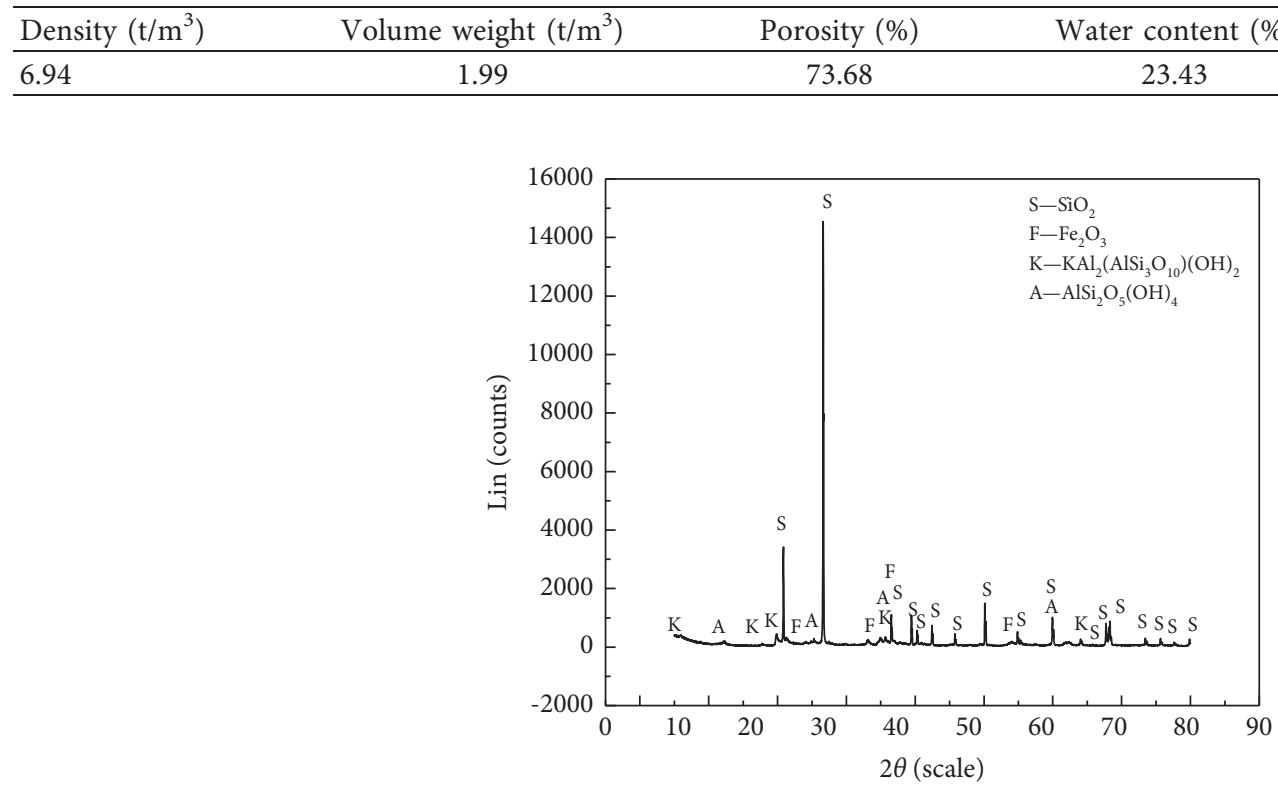

FIGURE 3: Red soil XRD diffraction analysis map.

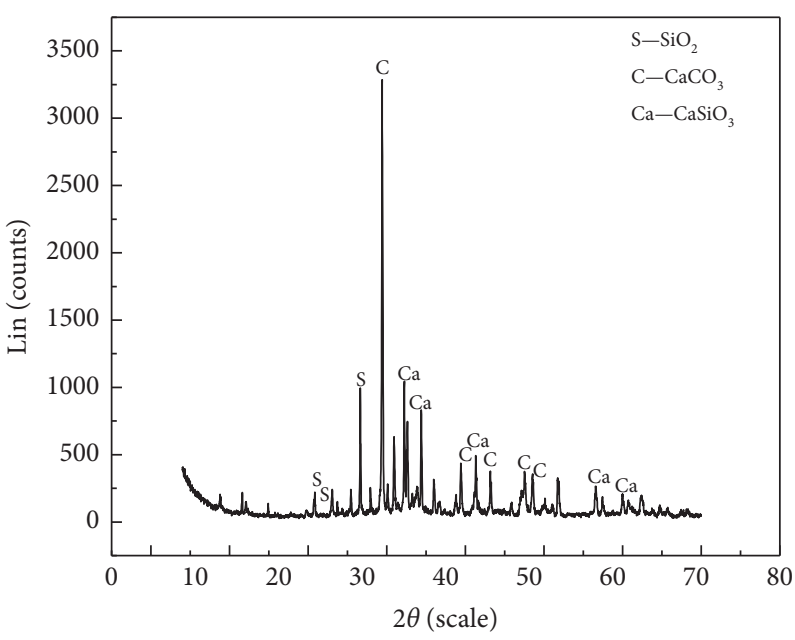

FIGURE 4: XRD diffraction pattern of cement.

TABLE 6: Table of test factors and levels.

\begin{tabular}{lccccccc}
\hline \multirow{2}{*}{ Trial number } & \multicolumn{3}{c}{ Influencing factors } & Trial number & $X(\%)$ & \multicolumn{2}{c}{ Influencing factors } \\
\hline 1 & $X(\%)$ & $Y$ & $Z$ (days) & & 78 & $1: 1$ \\
2 & 76 & $1: 1$ & 3 & 3 & 9 & 80 & $1: 1$ \\
3 & 78 & $1: 1$ & 3 & 10 & 82 & $1: 1$ \\
4 & 76 & $1: 1$ & 7 & 11 & 80 & 28 \\
5 & 78 & $1: 1$ & 7 & 12 & 80 & 28 \\
6 & 76 & $1: 1$ & 14 & 13 & 80 & 28 \\
7 & 78 & $1: 1$ & 14 & 14 & Plain cement & 28 \\
\hline
\end{tabular}

cluster ettringite crystals increase and gradually develop, overlap, and cross to form a tight network. From Figure 10(b), the coal zircon has been bonded and wrapped by a mass of generated reaction products, the thin particle content of red soil increases, and the overall structure is more encrypted. 


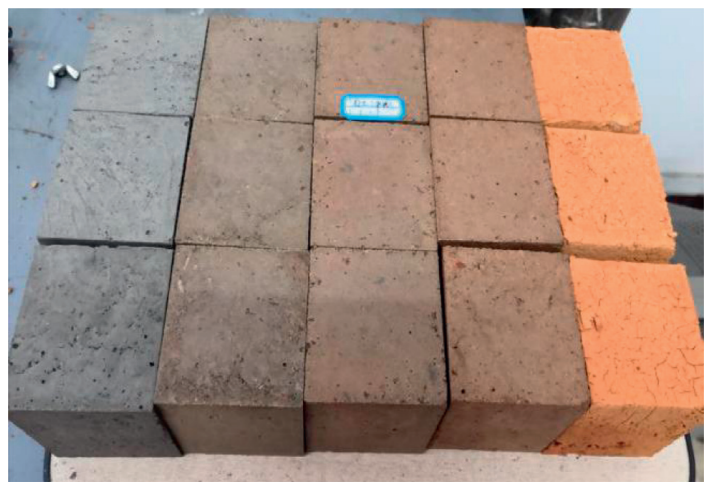

FIgURE 5: Part of the test after release.

TABle 7: Results of the paste performance test.

\begin{tabular}{|c|c|c|c|c|c|c|c|}
\hline \multirow{2}{*}{ Trial number } & \multicolumn{3}{|c|}{ Influencing factors } & \multirow{2}{*}{ Collapsing degree $(\mathrm{cm})$} & \multirow{2}{*}{ Bleeding rate (\%) } & \multirow{2}{*}{ Stone rate $(\%)$} & \multirow{2}{*}{ Compressive strength $(\mathrm{MPa})$} \\
\hline & $X(\%)$ & Y & $Z$ (days) & & & & \\
\hline 1 & 76 & $1: 1$ & 3 & 24.7 & 2.27 & 95 & 1.55 \\
\hline 2 & 78 & $1: 1$ & 3 & 22.5 & 1.77 & 96 & 2.53 \\
\hline 3 & 76 & $1: 1$ & 7 & 24.7 & 2.27 & 95 & 1.88 \\
\hline 4 & 78 & $1: 1$ & 7 & 22.5 & 1.77 & 97 & 2.69 \\
\hline 5 & 76 & $1: 1$ & 14 & 24.7 & 2.27 & 95 & 2.08 \\
\hline 6 & 78 & $1: 1$ & 14 & 22.5 & 1.77 & 98 & 3.58 \\
\hline 7 & 76 & $1: 1$ & 28 & 24.7 & 2.27 & 93 & 3.35 \\
\hline 8 & 78 & $1: 1$ & 28 & 22.5 & 1.77 & 99 & 4.53 \\
\hline 9 & 80 & $1: 1$ & 28 & 20.3 & 1.45 & 100 & 4.69 \\
\hline 10 & 82 & $1: 1$ & 28 & 16.5 & 1.31 & 100 & 7.64 \\
\hline 11 & 80 & $1: 2$ & 28 & 18.1 & 1.04 & 93 & 4.26 \\
\hline 12 & 80 & $2: 1$ & 28 & 21.5 & 1.93 & 100 & 6.42 \\
\hline 13 & 80 & Plain cement & 28 & 20.6 & 2.18 & 100 & 9.25 \\
\hline 14 & 80 & Plain red soil & - & 14.4 & 0.9 & 83 & 1.39 \\
\hline
\end{tabular}

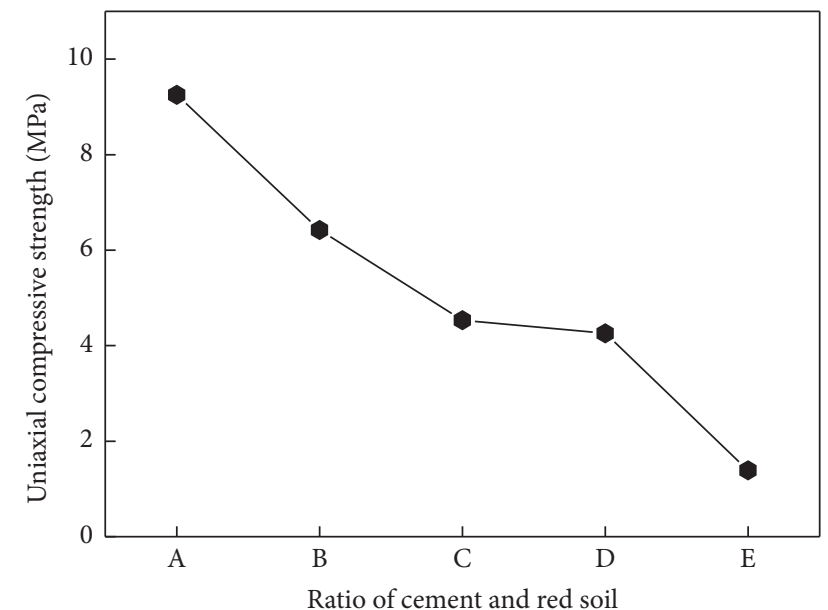

FIGURE 6: The law of influence between cement and red soil ratio on the strength of filling.

From Figure 11(a), when it reaches 28 days, the hydration reaction products increase greatly, and the distribution is wider and more intensive. No matter on the surface or in the rifts and pores, they are full of or filled with C-S-H gels. From Figure 11(b), compared with the curing age of 3

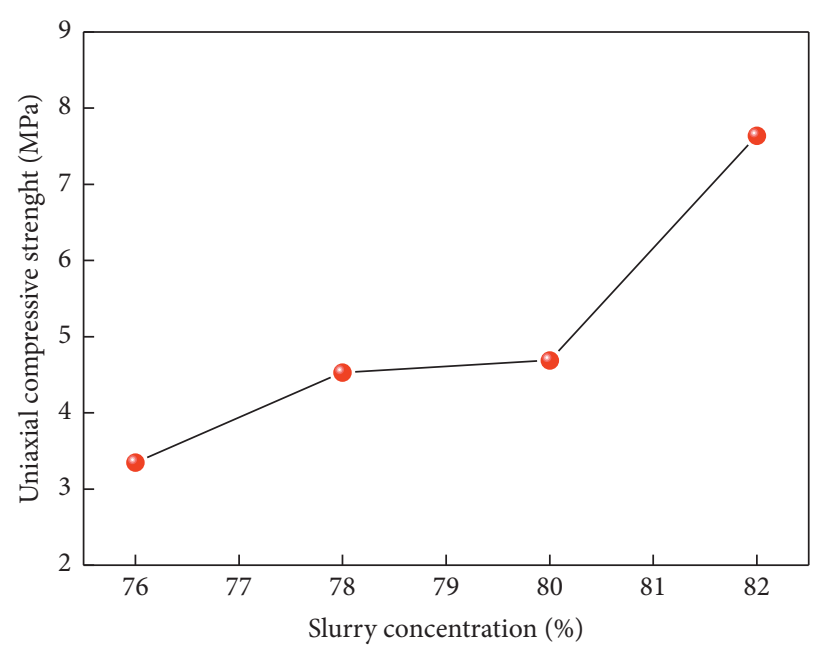

Figure 7: The law of influence of slurry concentration on the strength of filling.

days, the ettringite crystals are obviously thickened to be a rod-like structure and overlap with each other. The network structure of the hydration product and materials is denser, and no obvious cracks can be seen. In that moment, the strength of filling materials reached the maximum. 


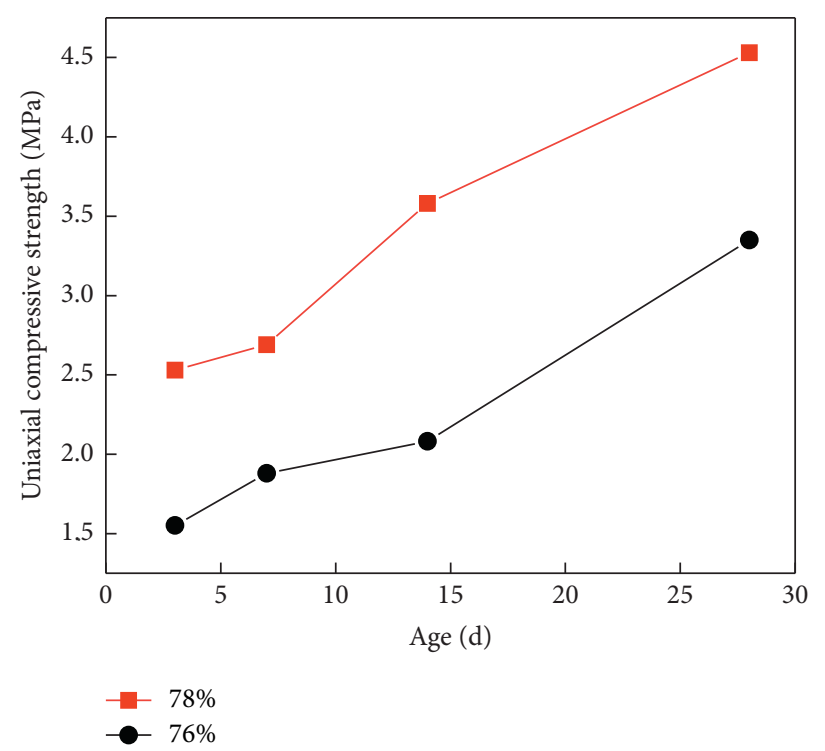

FIGURE 8: Variation in filling strength with age at different concentrations.

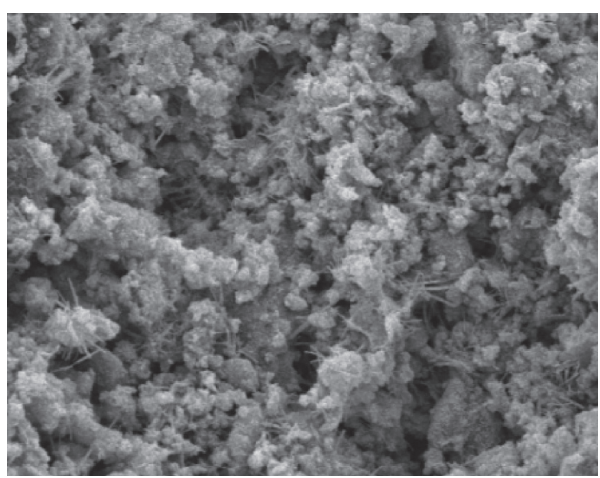

(a)

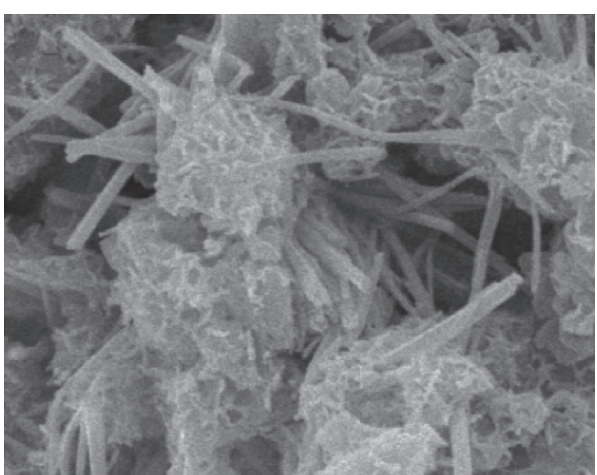

(b)

Figure 9: SEM diagram of 3 days of specimen maintenance: (a) $\times 500$; (b) $\times 5000$.

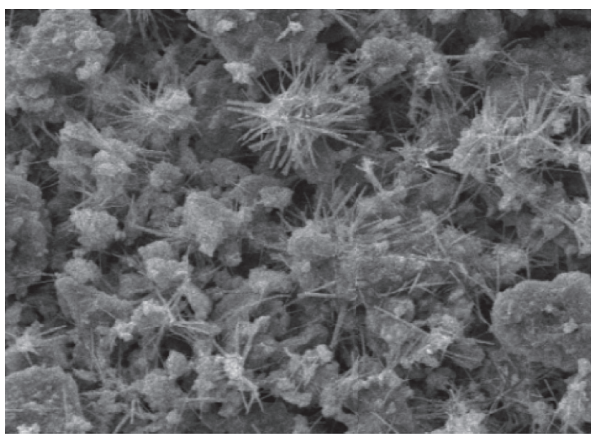

(a)

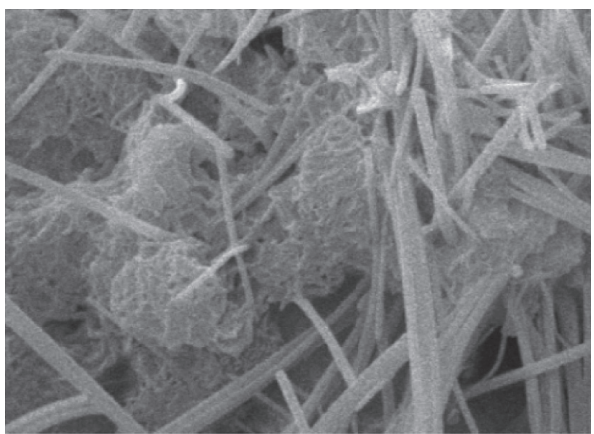

(b)

FIgURE 10: SEM diagram of 7 days of specimen maintenance: (a) $\times 500$; (b) $\times 5000$. 


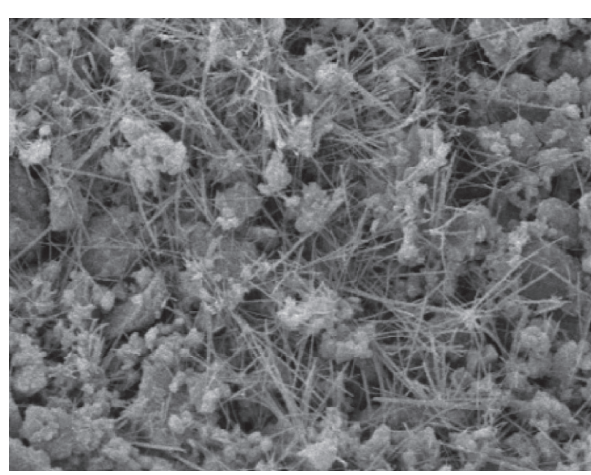

(a)

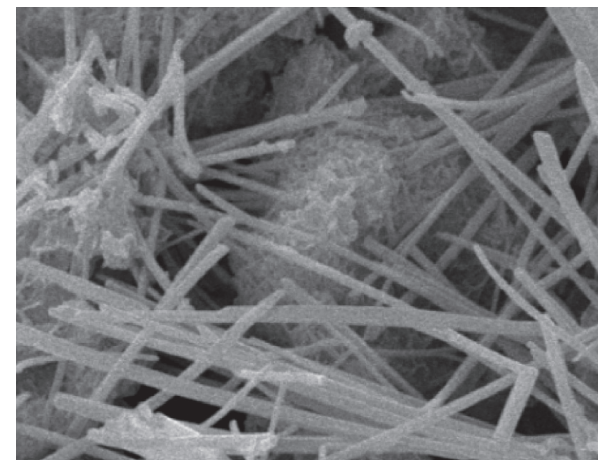

(b)

Figure 11: SEM diagram of 28 days of specimen maintenance: (a) $\times 500$; (b) $\times 5000$.
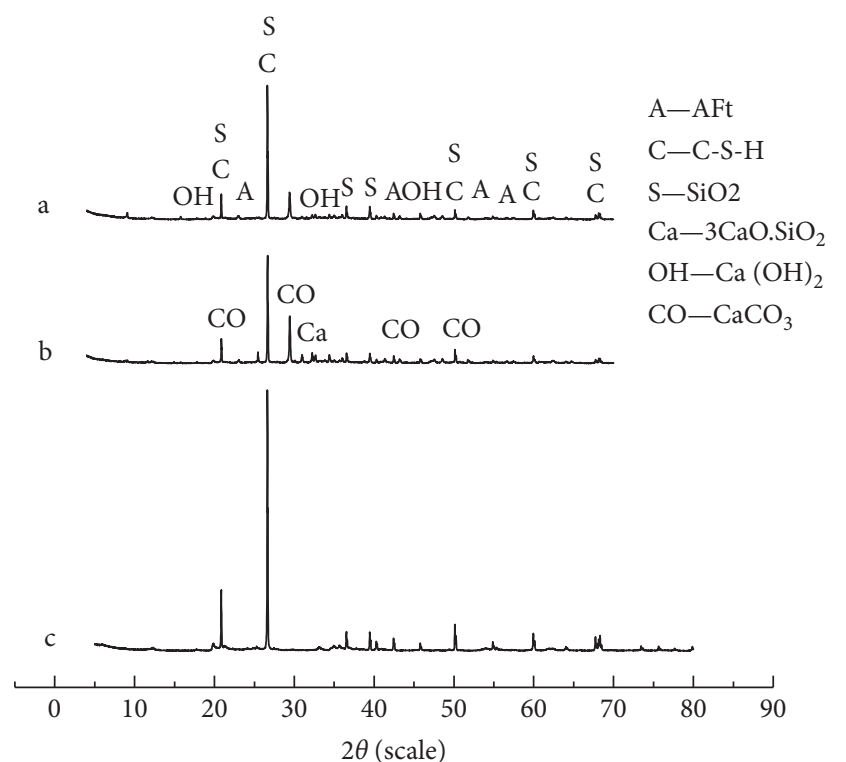

FIgURE 12: XRD diagram of different curing ages.

4.2. XRD Analysis of Filling Materials. The above dried test blocks were put in a mortar to grind; after screened into standard test pieces, they were then put into an XRD diffraction instrument for testing. The patterns (a) and (b) shown in Figure 12 are XRD diagrams of the samples for curing 3 days and curing 28 days, respectively. The pattern (c) shows the XRD diagram of red soil. Patterns (a) and (b) show that the C-S-H gel, $\mathrm{Ca}(\mathrm{OH})_{2}$, ettringite, gismondine, calcite, and quartz without complete hydration are the main hydration products of the new filling materials at different ages.

After 3 days of specimen maintenance, hydration reaction took place in the sample. However, most cement did not participate in the timely reaction, and the hydration products were mainly ettringite and scolecite. After 28 days of specimen maintenance, the product species were still the same as before; with the extension of curing age, the hydration reaction was more complete, and more ettringite and scolecite crystals were formed; the diffraction peaks of ettringite and scolecite were more obvious to maximize the strength of cementitious materials later.

The diffraction peaks of hydration reaction products are mainly between $20^{\circ}$ and $30^{\circ}$. Compared with the XRD pattern (c) of red soil, the diffraction peaks of hydration products at $5^{\circ}$ to $25^{\circ}$ are significantly reduced, and the diffraction peak region of $25^{\circ}$ to $35^{\circ}$ has a certain degree of protrusion, which is gradually obvious with the increase in curing age.

\section{Conclusions}

In this paper, the strength test and hydration mechanism of the new paste filling material are carried out by analyzing the physical and mechanical properties, mineral composition, and microstructure of the filling material. Based on the test results, the type and microstructure of hydration products are studied. The main conclusions are as follows:

(1) By analyzing the test materials, adding red soil to the paste filling material can increase the overall structural strength of the filling material and is useful for filling material with good particle gradation.

(2) Under uniaxial compression, slurry concentration is of the greatest influence than other factors on the strength of new paste filling material; the optimal ratio of the new paste filling material in the coal mine is the quality ratio of zircon: red soil: cement as $6: 2: 1$, and the slurry concentration is $80 \%$.

(3) When at 3 days of curing age, a mass floc-like scolecite and needle-like ettringite crystals are produced in the filling body, while ettringite is less poorly developed with small diameter. When at 28 days of curing age, the products of hydration reaction increase greatly, ettringite becomes thicker, and the network structure becomes more encrypted.

(4) The C-S- $\mathrm{H}$ gel, $\mathrm{Ca}(\mathrm{OH})_{2}$, and ettringite (AFt) are main hydration products of the new paste filling materials; as the age extends, the more complete the hydration reaction, the faster the content of ettringite 
and scolecite increases, while the content of $\mathrm{Ca}(\mathrm{OH})_{2}$ decreases gradually.

\section{Data Availability}

This article contains all the data generated during this study, and no other data were used to support this study.

\section{Conflicts of Interest}

The authors declare that they have no conflicts of interest.

\section{Acknowledgments}

This work was supported by the National Natural Science Foundation of China (no. 51974117) and Hunan Provincial Natural Science Foundation of China (no. 2020JJ4027).

\section{References}

[1] G. L. Hui, "The present situation and development of the coalfilling and mining technology in China," Coal Engineering, vol. 2, pp. 21-23, 2010.

[2] W. Yu, B. Pan, F. Zhang, S. Yao, and F. Liu, "Deformation characteristics and determination of optimum supporting time of alteration rock mass in deep mine," KSCE Journal of Civil Engineering, vol. 23, no. 11, pp. 4921-4932, 2019.

[3] W. J. Yu, G. S. Wu, B. F. An, and P. Wang, "Experimental study on the brittle-ductile response of a heterogeneous soft coal rock mass under multifactor coupling," Geofluids, vol. 2019, Article ID 5316149, 15 pages, 2019.

[4] K. Cheng, B. G. Yang, B. G. Zhang, D. Li, J. Yang, and R. Zhang, "Present situation and development direction of filling mining technology in coal mines in China," Coal Technology, vol. 37, no. 3, pp. 73-76, 2018.

[5] A. X. Wu, Y. Wang, and H. J. Wang, "Status and prospects of the paste backfill technology," Metal Mine, vol. 7, pp. 1-9, 2016.

[6] Z. D. Cui and H. H. Sun, "The preparation and properties of coal zircon based sialite paste-like backfill material," Journal of China Coal Society, vol. 35, no. 6, pp. 896-899, 2010.

[7] Y. Z. Rao, "Mix ratio test of low cost filling cementitious materials," China Mining Magazine, vol. 7, no. 5, pp. 26-29, 1998.

[8] Z. S. Wang and K. H. Sun, "Experimental study on mine-loess paste filling material," Bulletin of the Chinese Ceramic Society, vol. 33, no. 6, pp. 1470-1474, 2014.

[9] S. K. Behera, C. N. Ghosh, K. Mishra et al., "Utilization of lead-zinc mill tailings and slag as paste backfill materials," Environmental Earth Sciences, vol. 79, no. 16, pp. 2-6, 2020.

[10] A. K. Gupta and B. Paul, "A review on utilisation of coal mine overburden dump waste as underground mine filling material: a sustainable approach of mining," International Journal of Mining and Mineral Engineering, vol. 6, no. 2, pp. 172-186, 2015.

[11] V. V. Phan and D. Wang, "Experimental study on proportioning of bottom ash in thermal power plant as paste filling material of coal mine," Journal of Safety Science and Technology, vol. 14, no. 1, pp. 49-55, 2018.

[12] S. S. Zhang, X. H Yang, S. J Xie, and P. J. Yin, "Experimental study on improving the engineering properties of coarse grain sulphate saline soils with inorganic materials," Cold Regions Science and Technology, vol. 170, Article ID 102909, 2020.
[13] G. M. Feng, C. D. Sun, C. Z. Wang, and Z. Zhou, "Research on goaf filling methods with super high-water material," Journal of China Coal Society, vol. 35, no. 12, pp. 1963-1968, 2010.

[14] S. Zhou, "Research and application on filling mining in underhand mining with superhigh-water material," China University of Mining and Technology, vol. 3, 2014.

[15] B. F. An, W. J. Yu, G. S. Wu, and C. L. Wang, "Plastic zone and stress evolution of pillars in working face with solid backfilling mining to recover room coal pillars," Journal of Mining Safety Engineering, vol. 36, no. 3, pp. 609-616, 2019.

[16] W. J. Yu and F. F. Liu, "Stability of close chambers surrounding rock in deep and comprehensive control technology," Advances in Civil Engineering, vol. 2018, Article ID 6275941, 18 pages, 2018.

[17] W. J. Yu, S. H. Zhai, and Q. Gao, "Stability evaluation indexes of deep stope pillar and roadway surrounding rock," Disaster Advances, vol. 5, no. 4, pp. 120-126, 2012.

[18] W. B. Sun and C. W. Luo, "Research on proportion of backfill material in coal mine," Safety in Coal Mines, vol. 49, no. 4, pp. 55-57, 2018.

[19] C. Z. Zhao, H. Q. Zhou, J. B. Bai, and H. Qiang, "Influence factor analysis of paste filling material strength," Journal of Liaoning Technical University, vol. 25, no. 6, pp. 904-906, 2006.

[20] W. B. Sun, H. H. Sun, J. Z. Liu, and Z. Q. Rao, "Research on proportion of paste-like backfilling material," China Mining Magazine, vol. 14, no. 5, pp. 70-71, 2005. 